\title{
Preparation of cationic polyacrylamide microsphere emulsion and its performance for permeability reduction
}

\author{
Guo Aijun', Geng Yiran'1, Zhao Lili' ${ }^{1}$ Li Jun², Liu Dong ${ }^{1}$ and Li Peng ${ }^{1 *}$ \\ ${ }^{1}$ State Key Laboratory of Heavy Oil Processing and College of Chemical Engineering, China University of Petroleum (East \\ China), Qingdao, Shandong 266580, China \\ ${ }^{2}$ Technical Department of Ethylene Complex, Petrochina Dushanzi Petrochemical Company, Karamayi, Xinjiang 833600, \\ China
}

(C) China University of Petroleum (Beijing) and Springer-Verlag Berlin Heidelberg 2014

\begin{abstract}
In this paper, cationic polyacrylamide microspheres (CPAM) were synthesized using acrylamide (AM) and methacryloyloxyethyl trimethyl ammonium chloride (TMAEMC) as monomers, ammonium sulfate as dispersant, poly(acryloyloxyethyl trimethyl ammonium chloride) (PAETAC) as dispersion stabilizer, and ammonium persulfate as initiator. The synthetic method was dispersion polymerization. The effects of monomer ratio (AM/TMAEMC), dispersant concentration, and dispersion stabilizer dosage on dispersion polymerization were systematically studied to determine the optimal preparation conditions. The structure and viscosity of the synthesized polymer were characterized by FTIR and capillary viscometry, respectively, and the particle sizes and distribution of the polymer microspheres were characterized by microscopy and dynamic light scattering, respectively. Finally, flow tests were conducted to measure the permeability reduction performance of the microspheres at various concentrations in sand packs with different permeability. Results show that CPAM emulsion of a solids content of $1 \mathrm{wt} \%$ has excellent performance in low-to-medium permeability formations $(<1,000 \mathrm{mD})$, and the efficiency may reach above $90 \%$.
\end{abstract}

Key words: Dispersion polymerization, cationic polyacrylamide microspheres, profile modification, permeability reduction

\section{Introduction}

During a secondary or enhanced oil recovery process, a substantial amount of oil may be bypassed by the injected fluid due to reservoir heterogeneity and the water cut of the produced fluids may be very high (Yu et al, 2011; Xiao and Wang, 2003; Fletcher et al, 1992; Liu et al, 2006). In order to enhance oil recovery, the widely used method is injecting water cutoff materials to control formation permeability and then to divert the follow-up injected fluid into the unswept zones, without damaging oil productivity (Hou et al, 2011; Lu et al, 2012; Shi et al, 2010; 2012; Dong et al, 2010). So it is necessary to synthesize a new water cutoff material to reduce water cut of produced fluids and improve oil-producing efficiency in formations (Fielding et al, 1994; Ning et al, 2007; Lin et al, 2008; 2009; Lu et al, 2010; Feng et al, 2010; Wang and Li, 2011; Qiao et al, 2012).

Polymer microspheres are newly developed water cutoff material. After hydration, swollen polymer microspheres

*Corresponding author. email: Lip@upc.edu.cn

Received February 13, 2014 progressively adsorb and deposit in pore throats to closure fluid channels in the formations. There are many advantages for such permeability control treatment: the dispersed polymer microsphere emulsion has relatively low viscosity; formation water produced in oilfields may be used to prepare the polymer microsphere emulsion; and the most important is that the microspheres may be injected into formations continuously (Lei et al, 2011; Lin et al, 2003; 2011a; 2011b). However, most polymer microspheres are nonionic, showing weak interaction with clay. In order to enhance the interaction between polymer microspheres with clay, this investigation tries to incorporate cationic monomer into polymers.

Water dispersion polymerization is also a newly developed process for synthesizing polymer microspheres. This technology is simple in operation, and water is used, instead of organic solvent, to dissipate heat during reaction; hence, secondary pollution and environmental impact can be reduced. Therefore, research into water dispersion methods has important theoretical and practical values (Cho et al, 2002; Grazon et al, 2011; Semsarilar et al, 2012; Wang et al, 2011a; 2011b; 2011c; Liu et al, 2011; 2012; Ondaral et al, 
2010; Song et al, 2003; Wu et al, 2008).

\section{Experimental}

\subsection{Experimental materials}

Acrylamide (AM, 99.0\%), ammonium sulfate (AS, $99.0 \%$ ), ammonium persulfate (APS, $\geq 98.0 \%$ ), $N, N^{\prime}$ methylenediacrylamide (MEDAM, 96.0\%), and sodium bicarbonate $(99.8 \%)$ used in experiments were all purchased from the China National Medicines Corporation Ltd.; methacryloyloxyethyl trimethyl ammonium chloride (TMAEMC, $75.0 \mathrm{wt} \%$ in water) and acryloyloxyethyl trimethyl ammonium chloride (AETAC, $75.0 \mathrm{wt} \%$ in water) were purchased from the Penglai Spark Chemical Co., Ltd. $\mathrm{AM}$ and TMAEMC were used as monomers, AS and sodium bicarbonate as dispersants, and MEDAM as a crosslinker.

\subsection{Preparation of cationic polyacrylamide microspheres}

2.2.1 Synthesis of a cationic dispersion stabilizer, poly(acryloyloxyethyl trimethyl ammonium chloride) (PAETAC)

Two grams of AETAC was dissolved in $50 \mathrm{~mL}$ deionized water, which was then added to a three-necked flask. Nitrogen was kept flowing through the flask for $45 \mathrm{~min}$ and then the bath temperature was increased to $60^{\circ} \mathrm{C}$. APS, as an initiator, was added to the flask so that the reaction took place at this temperature for 1-2 $\mathrm{h}$ under stirring. Afterwards the reaction temperature was further increased to $75^{\circ} \mathrm{C}$ and the reaction time was extended for about $3 \mathrm{~h}$ at this temperature. Nitrogen<smiles>CC(=C[CH+]CCCCC(N)=O)C(=O)OCC[N+](C)(C)CCl</smiles>

\subsection{IR characterization}

The copolymer after purification was dried to constant weight and pressed with $\mathrm{KBr}$ to disc form, and then a Fourier transform infrared spectrometer (NEXUS, Nicolet Co., USA) was used to characterize the cationic acrylamide polymer structure.

\subsection{Determination of viscosity of the copolymer}

The apparent viscosity of the crude product was determined with a NDJ-1 rotary viscometer. The dried CPAM was dissolved in deionized water to prepare a CPAM emulsion with a solids content of $1 \%(\mathrm{w} / \mathrm{v}, 0.01 \mathrm{~g} / \mathrm{mL})$, and the viscosity of this emulsion is the intrinsic viscosity of cationic polyacrylamide.

\subsection{Morphology of CPAM before and after hydrolysis}

The purified CPAM was dissolved in deionized water was kept flowing during the whole synthesis process, and the final product, poly(acryloyloxyethyl trimethyl ammonium chloride) (PAETAC), was a viscous, brown liquid. The reaction equation of the cationic stabilizer is described as follows:

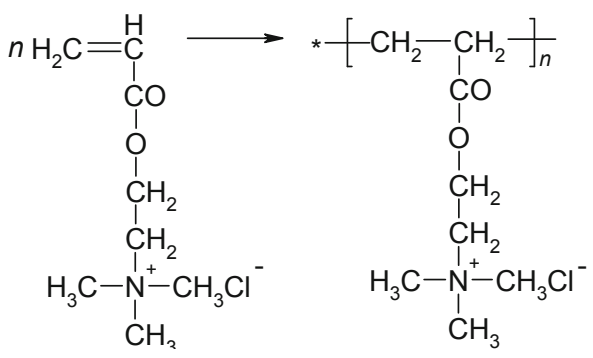

\subsubsection{Synthesis of cationic polyacrylamide microspheres (CPAM)}

Monomers of AM and TMAEMC were weighed and put into a three-necked flask. Then ammonium sulfate, sodium bicarbonate, synthesized PAETAC solution, and deionized water were added and nitrogen was kept flowing for $20 \mathrm{~min}$. After the temperature was increased to $50^{\circ} \mathrm{C}$, APS was added dropwise. When the reaction was over, the reaction mixture was cooled to room temperature for discharging. The crude product was a white emulsion with good fluidity and stability. Acetone was added to the crude product slowly, and the CPAM precipiated at the bottom gradually. After filtration, the CPAM was dissolved in deionized water again, and then precipitated by acetone; this process was repeated three times. At last, the CPAM was dried in an oven at $50{ }^{\circ} \mathrm{C}$ for $24 \mathrm{~h}$. The main reaction is described as follows.

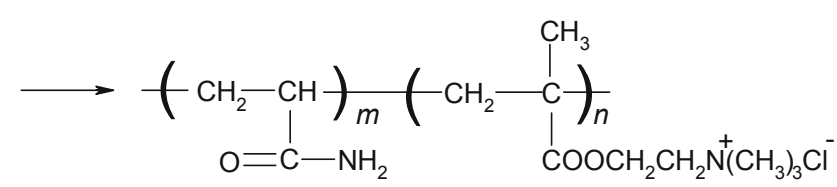

Cationic polyacrylamide

to obtain a dispersion system with a solids content of $1 \%$, and $\mathrm{NaOH}$ solution was used to adjust the $\mathrm{pH}$ to 9 . Then the sample was hydrated for $24 \mathrm{~h}$ at $65{ }^{\circ} \mathrm{C}$. The morphology of CPAM in water before and after hydrolysis was observed with an inverted fluorescence microscope (XP-221, Jiangnan Yongxin Co.).

\subsection{Particle size of CPAM}

CPAM dispersions before and after hydrolysis were prepared as above, and $1 \mathrm{~mL}$ dispersions were put in a dynamic light scattering analyzer which was pre-heated for $30 \mathrm{~min}$, and the microsphere sizes of CPAM in water were measured.

\subsection{Performance of CPAM emulsion for permeability reduction}

The porous media used was compacted packs of quartz sand (100-200 mesh). The sand packs were $52 \mathrm{~cm}$ long and 2.6 
$\mathrm{cm}$ in diameter.

CPAM emulsions were prepared by dissolving CPAM in deionized water, and the salinity of the emulsions was adjusted with $\mathrm{NaCl}, \mathrm{KCl}, \mathrm{MgCl}_{2}$, and $\mathrm{CaCl}_{2}$.

The performance of CPAM emulsion for permeability reduction was investigated with the equipment shown schematically in Fig. 1 and the experimental procedures are described as follows:

1) The sand pack was dried, evacuated and saturated with water at a rate of $1 \mathrm{~mL} / \mathrm{min}$ in order to determine its pore volume (PV), porosity and permeability. During water injection the pressure was recorded every $2 \mathrm{~min}$.
2) 0.3 PV CPAM emulsion was injected into the sand pack at a rate of $1 \mathrm{~mL} / \mathrm{min}$ and the pressure was monitored.

3 ) The sand pack was taken out of the core holder and placed in a $65^{\circ} \mathrm{C}$ oven.

4) After $24 \mathrm{~h}$, the sand pack was removed from the oven and cooled to room temperature.

5) The sand pack was installed at the core holder and then water was injected at a rate of $1 \mathrm{~mL} / \mathrm{min}$ until the injection pressure was stabilized. During water injection the temperature and pressure were recorded every 2 min. Finally the permeability and permeability reduction of the sand pack after treatment were calculated.

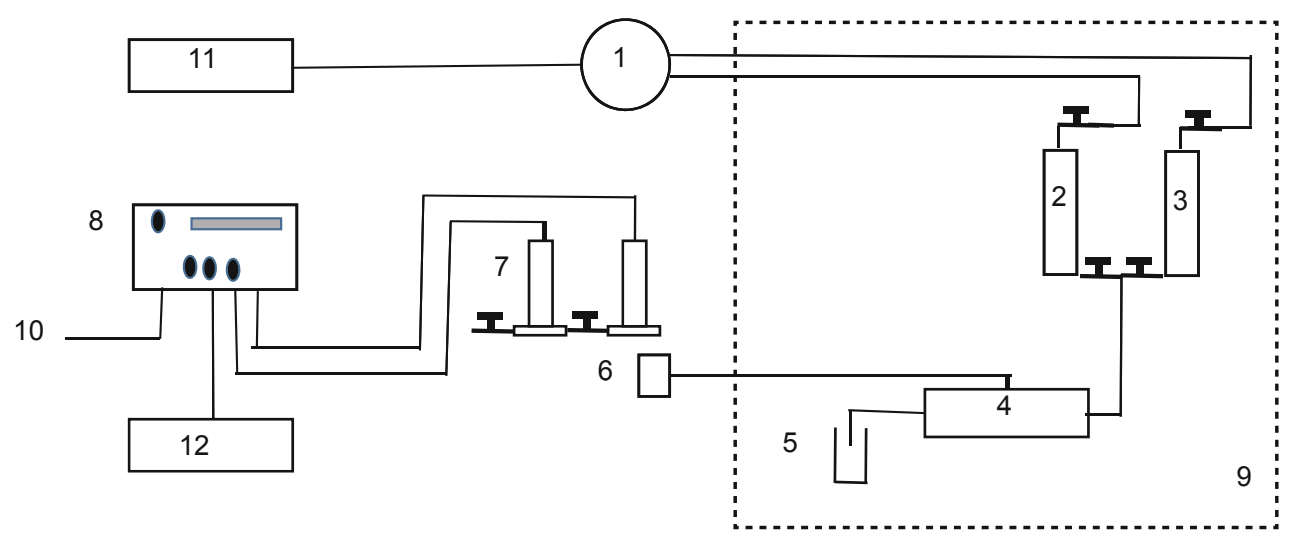

Fig. 1 Experimental apparatus for flow experiments

1-6-way valve; 2-CPAM emulsion tank; 3-water tank; 4-core holder; 5-beaker; 6-ring pump; 7-pressure sensor; 8-digital pressure instrument; 9-constant temperature bath; 10-power; 11-micro-pump; 12-computer

\section{Results and discussion}

\subsection{Dispersion polymerization of CPAM}

CPAM was synthesized in laboratory and the effects of monomer molar ratio, stabilizer concentration, and APS concentration on polymerization reaction were investigated.

\subsubsection{Dispersion stabilizer concentration}

The effect of stabilizer (PAETAC) concentration on aqueous dispersion polymerization was investigated under the following reaction conditions: total monomer concentration (AM and TMAEMC), 15wt $\%$; AM/TMAEMC molar ratio, $8: 2$; APS concentration, $1 \mathrm{wt} \%$; AS concentration, $30 \mathrm{wt} \%$; and reaction temperature, $50{ }^{\circ} \mathrm{C}$.

Table 1 shows the effect of PAETAC concentrations.
With an increase in the PAETAC concentration, the intrinsic viscosity of the cationic polyacrylamide emulsion decreased, while the apparent viscosity of the crude product increased when the PAETAC concentration was 0.5-0.6 g/g-monomer; when the PAETAC concentration was lower than $0.4 \mathrm{~g} /$ g-monomer, the crude product was uneven and unstable; when the PAETAC concentration was more than $0.5 \mathrm{~g} /$ g-monomer, the obtained CPAM were substantially spherical, and most of these particles were within the range of tens of nanometers, with an even distribution. If the PAETAC concentration continued to increase, the particle sizes of the obtained CPAM were reduced accordingly, therefore, the optimal PAETAC concentration adopted in the experiment was $0.5 \mathrm{~g} / \mathrm{g}$-monomer.

Table 1 The effect of PAETAC concentration on CPAM dispersion polymerization

\begin{tabular}{ccccc}
\hline No. & $\begin{array}{c}\text { PAETAC concentration } \\
\text { g/g-monomer }\end{array}$ & $\begin{array}{c}\text { Intrinsic viscosity of } \\
\text { CPAM emulsion, dL/g }\end{array}$ & $\begin{array}{c}\text { Viscosity of CPAM } \\
\text { crude product, } \mathrm{mPa} \cdot \mathrm{s}\end{array}$ & Morphology and stability of the crude product \\
\hline 1 & 0.3 & - & - & $\begin{array}{c}\text { Gel appeared in the early stage of polymerization } \\
\text { White-pink emulsion with good fluidity, a layer of } \\
\text { CPAM was seperated after standing }\end{array}$ \\
2 & 0.4 & 3.27 & 800 & White-pink emulsion with fluidity, no separation \\
3 & 0.5 & 3.02 & 3150 & White-pink emulsion with fluidity, no separation \\
\hline
\end{tabular}




\subsubsection{AM/TMAEMC molar ratio}

The effect of the AM to TMAEMC molar ratio was investigated under the following conditions: total monomer concentration of $15 \mathrm{wt} \%$, APS concentration, $1 \mathrm{wt} \%$; AS concentration, $30 \mathrm{wt} \%$; reaction temperature, $50{ }^{\circ} \mathrm{C}$. The experimental results are listed in Table 2.

Table 2 Effect of AM/TMAEMC molar ratio on CPAM dispersion polymerization

\begin{tabular}{ccccc}
\hline No. & AM/TMAEMC molar ratio & $\begin{array}{c}\text { Intrinsic viscosity } \\
\text { of CPAM, dL/g }\end{array}$ & $\begin{array}{c}\text { Viscosity of CPAM crude } \\
\text { product, } \mathrm{mPa} \cdot \mathrm{s}\end{array}$ & Morphology and stability of the crude product \\
\hline 5 & $9: 1$ & 3.54 & Very viscous & White jelly \\
6 & $8: 2$ & 3.02 & 3150 & White-pink emulsion with fluidity, no separation \\
7 & $7: 3$ & 2.74 & 850 & $\begin{array}{c}\text { Dark pink emulsion with fluidity, no separation } \\
\text { Brown-pink emulsion with good fluidity, a layer of } \\
\text { CPAM was seperated after standing, unstable }\end{array}$ \\
\hline
\end{tabular}

Table 2 indicates that when the AM/TMAEMC molar ratio was in a range from $9: 1$ to $6: 4$, the intrinsic viscosity of CPAM emulsion decreased with a decrease in the AM/ TMAEMC molar ratio. With a high concentration of TMAEMC, collisions among monomers decreased due to electrostatic repulsion, so the growth of molecular chains was restricted, and thus the intrinsic viscosity of the CPAM emulsion reduced as well as the apparent viscosity. Therefore, an AM/TMAEMC molar ratio of $8: 2$ was selected to synthesize cationic polyacrylamide.

\subsubsection{AS concentration}

At a total concentration of monomers of $15 \mathrm{wt} \%$, APS concentration of $1 \mathrm{wt} \%, \mathrm{AM} / \mathrm{TMAEMC}$ molar ratio of $8: 2$, and reaction temperature of $50{ }^{\circ} \mathrm{C}$, the effect of the AS concentration during polymerization reaction was investigated, and the results are shown in Table 3.

Table 3 Effect of AS concentration on CPAM dispersion polymerization

\begin{tabular}{ccccc}
\hline No. & $\begin{array}{c}\text { AS concentration } \\
\mathrm{wt} \%\end{array}$ & $\begin{array}{c}\text { Intrinsic viscosity } \\
\text { of CPAM emulsion, dL/g }\end{array}$ & $\begin{array}{c}\text { Viscosity of CPAM crude } \\
\text { product, Pa } \cdot \text { s }\end{array}$ & Morphology and stability of the crude product \\
\hline 9 & 25 & 2.58 & Poor fluidity & Gelatinous \\
10 & 27 & 2.92 & 13000 & White-pink emulsion with fluidity \\
11 & 30 & 3.04 & 12500 & White-pink emulsion with fluidity \\
12 & 33 & 2.79 & 4400 & White-pink emulsion with fluidity, no separation \\
\hline
\end{tabular}

Table 3 indicates that the AS concentration had a significant effect on the intrinsic viscosity of the CPAM emulsion. As the AS concentration increased, the intrinsic viscosity first increased and then decreased. The reason is as follows: When the AS concentration is relatively low, the salting-out effect is weak and the reaction mainly takes place in the continuous phase. Therefore, the relative molecular weight of the copolymer is low. With an increase in the AS concentration, the polymerization may occur in the polymer phase, gradually transferred from the continuous water phase, in which the gel effect may exist during the transformation. Therefore, the growth time of free radicals in the polymer phase may be long, so the molecular weight of the copolymer increases as well. However, if the AS concentration is higher than $30 \%$, the reaction may take place in the water phase again, but not the polymer phase, which results in a reduction of the molecular weight of cationic polyacrylamide. The above analysis indicates that $27 \mathrm{wt} \%-30 \mathrm{wt} \%$ sulfate nitrate solution will help to obtain polymer products with uniform particle size and good stability.

Therefore, the optimal synthesis conditions are as follows: the total concentration of monomers of $15 \mathrm{wt} \%$; $\mathrm{AM}$ to TMAEMC molar ratio of $8: 2$; APS concentration of $1 \mathrm{wt} \%$; reaction temperature of $50{ }^{\circ} \mathrm{C}$, and an $\mathrm{AS}$ concentration of $30 \mathrm{wt} \%$.

\subsection{Characterization of CPAM}

\subsubsection{Infrared spectrum analysis}

It can be seen from the IR spectrum of CPAM (Fig. 2) that the absorption peak at $3,476 \mathrm{~cm}^{-1}$ and $3,180 \mathrm{~cm}^{-1}$ are peaks of symmetric and asymmetric stretching vibrations of $\mathrm{N}-\mathrm{H}$ bonds of amide, respectively. The absorption at $1,680 \mathrm{~cm}^{-1}$ is the symmetric stretching vibration of $\mathrm{C}=\mathrm{O}$ in amide, and absorption peak at $1,740 \mathrm{~cm}^{-1}$ is due to the $\mathrm{C}=\mathrm{O}$ stretching vibration for acyloxy. The absorption peak at $1,402 \mathrm{~cm}^{-1}$ is attributed to bending vibration of methylene in a cationic monomer $-\mathrm{CH}_{2}-\mathrm{N}^{+}\left(\mathrm{CH}_{3}\right)_{3}$, and the sharp absorption peak at $1,109 \mathrm{~cm}^{-1}$ is characteristic of the $\mathrm{C}-\mathrm{O}$ vibration in ester groups.

\subsubsection{Inverted fluorescence microscope observation}

The CPAM were hydrolyzed at $65{ }^{\circ} \mathrm{C}$ and alkaline conditions $(\mathrm{pH}=9)$, and an inverted fluorescence microscope was used to observe the changes of CPAM in water before and after hydrolysis, as shown in Fig. 3.

Fig. 3(a) shows the morphology of the CPAM just dissolved in water observed with the inverted fluorescence 


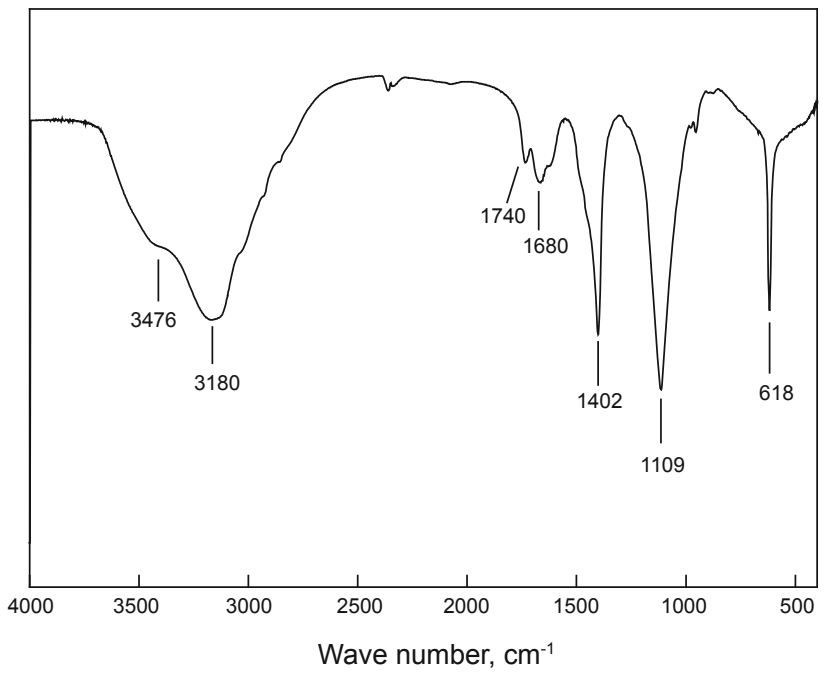

Fig. 2 Infrared spectrum of CPAM

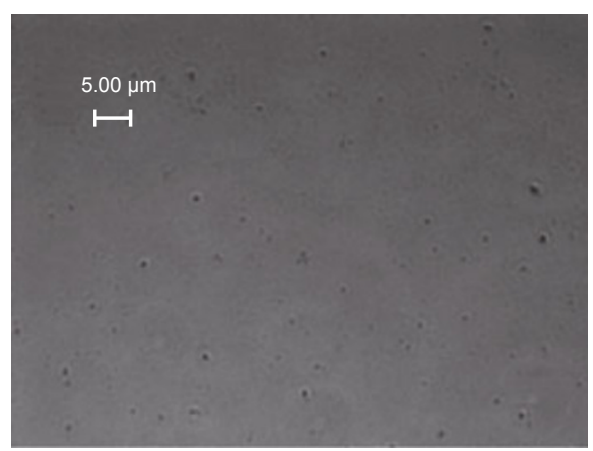

(a) Prior to hydrolysis

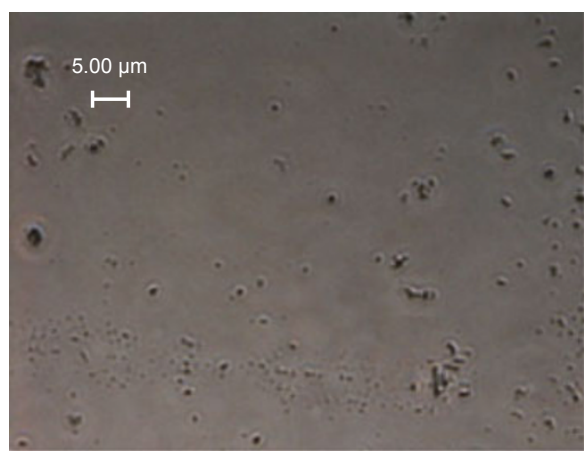

(b) After hydrolysis

Fig. 3 Inverted fluorescence microscopy images of CPAM before and after hydrolysis

microscope, where the polymer particles are very small and barely visible in this figure.

Fig. 3(b) shows the morphology of CPAM after swelling in water at $\mathrm{pH}=9$ for $24 \mathrm{~h}$. Many micrometer-sized spherical particles were observed. Therefore, the synthetic polymer microspheres exhibit significant swelling behavior caused by hydrolysis under alkaline conditions and the particle size may swell from nanometers to microns which meets the requirements for reducing the reservoir permeability.

\subsubsection{Dynamic light scattering analysis}

Fig. 4 shows the particle size distribution of CPAM synthesized under the optimal conditions. As can be seen from the figure, the particle sizes were mainly distributed from $7 \mathrm{~nm}$ to $100 \mathrm{~nm}$, with an average diameter of $31 \mathrm{~nm}$.

Fig. 5 (a) shows the particle diameter distribution by intensity of CPAM synthesized under the optimum conditions, dissolved, dispersed and swollen in water at $\mathrm{pH}=9$. As can be seen from the figure, the particles were mainly distributed in the range of 160-1,020 nm, with an average particle size of $348 \mathrm{~nm}$. Fig. 5(b) is the corresponding particle distribution by number, where the proportion of particle numbers reached $100 \%$ in $140-1,000 \mathrm{~nm}$, without other peaks. This shows that the CPAM hydrolysis and swelling did occur at $\mathrm{pH}=9$, leading to a tenfold increase in diameter. The observed results agree with the theoretical analysis.

Fig. 6(a) shows the particle diameter distribution by intensity of CPAM swollen in water at $\mathrm{pH}=11$. The CPAM used were synthesized under optimal conditions. It can be seen from the figure that the particles were mainly distributed in 150-1,200 nm, with an average particle size of $346 \mathrm{~nm}$. Fig. 6(b) is the corresponding particle distribution by number. Within the range of 130 to $1,000 \mathrm{~nm}$, the number of CPAM reached $100 \%$ without other peaks.

It can be calculated from Figs. 5 and 6 that CPAM expanded 11.3 and 11.2 times of the initial size at $\mathrm{pH}=9$ and $\mathrm{pH}=11$ conditions, respectively.

To sum up, the CPAM synthesized under optimized conditions were found to be ten nanometers to several tens of nanometers in diameter before hydrolysis; when they

Size distribution by intensity

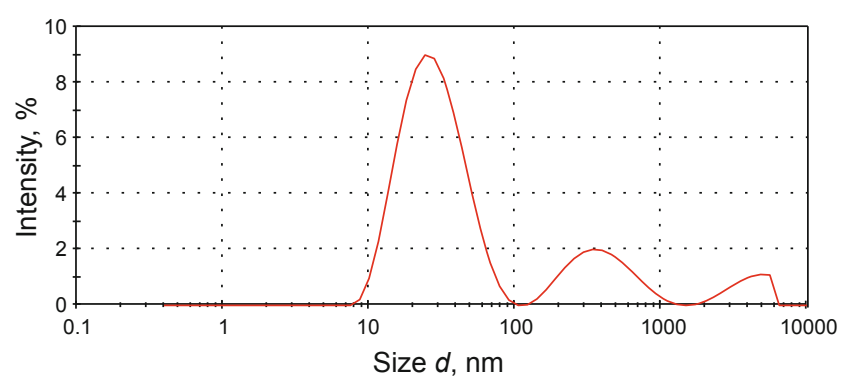

(a) Particle size distribution by intensity

Size distribution by number

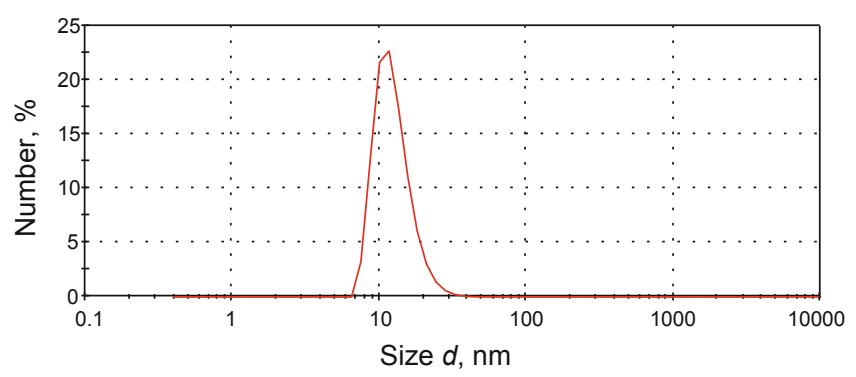

(b) Particle size distribution by number

Fig. 4 Particle size distribution of CPAM in water $(\mathrm{pH}=7)$ prior to hydrolysis 


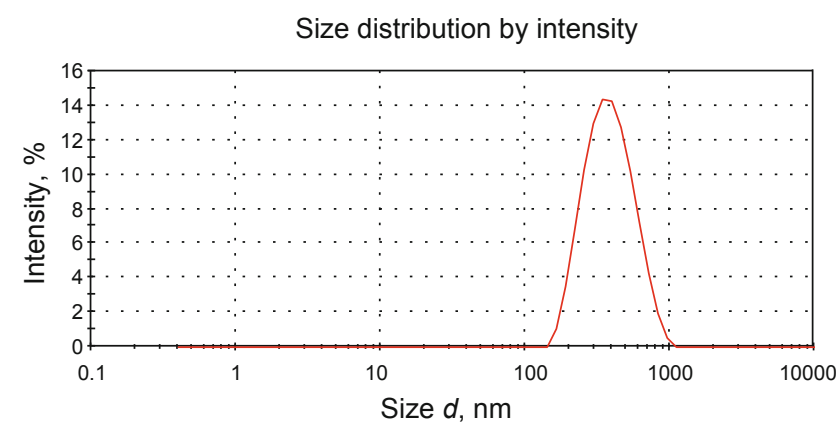

(a) Particle size distribution by intensity

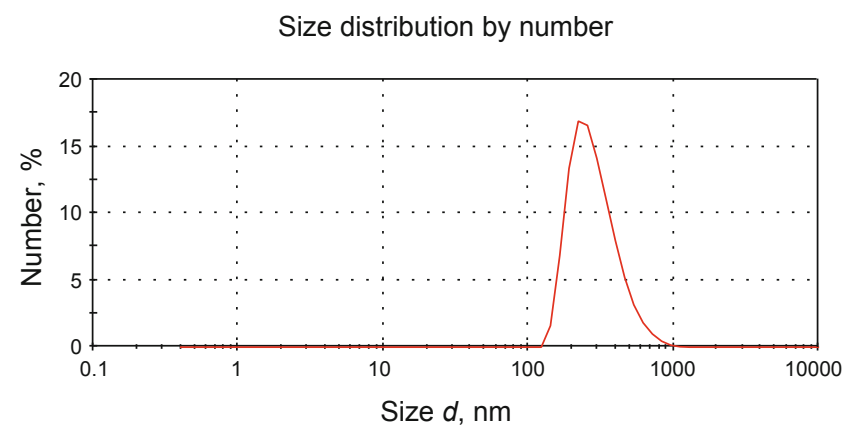

(b) Particle size distribution by number

Fig. 5 Particle size distribution of CPAM after hydrolysis in water at $\mathrm{pH}=9$

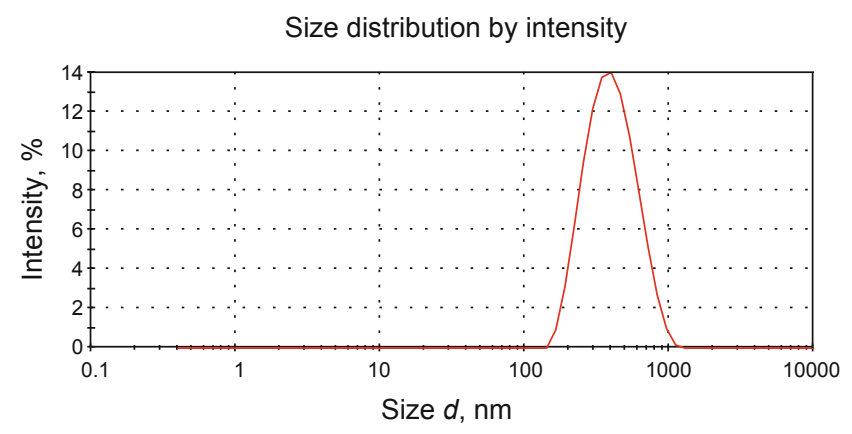

(a) Particle size distribution by intensity

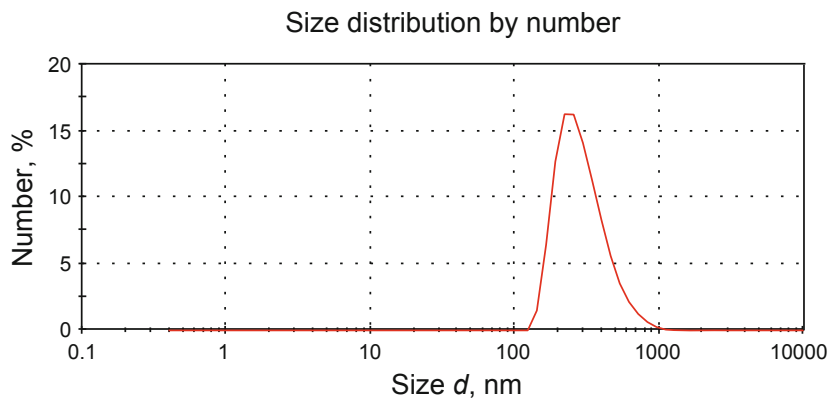

(b) Particle size distribution by number

Fig. 6 Particle size distribution of CPAM after hydrolysis in water at $\mathrm{pH}=11$

hydrolyzed and swollen in water for $24 \mathrm{~h}$ under alkaline conditions, their particles were of $300-400 \mathrm{~nm}$, and there is no significant difference between diameters of the hydrolyzed
CPAM swelling in $\mathrm{pH}=9$ and $\mathrm{pH}=11$ solutions.

\subsection{Permeability reduction performance of CPAM}

\subsubsection{Effect of CPAM concentration}

CPAM synthesized under optimum conditions were selected to formulate emulsions with a solid content of $0.3 w t \%, 0.5 w t \%, 1 w t \%$, and $2 w t \%$. The sand packs used had an average porosity of $26.9 \%$ and permeability of $339-504$ $\mathrm{mD}$.

Fig. 7 shows curves of injection pressure versus with time (injected volume) before and after CPAM injection. Fig. 7(a) shows that after 0.3 PV CPAM emulsion of $0.3 \mathrm{wt} \%$ solids content was injected into the sand pack, the injection pressure gradually increased to a peak value of 2.0 $\mathrm{MPa}$ and then decreased to a plateau level of $1.8 \mathrm{MPa}$ when water was continuously injected. This means that after water breakthrough, which occurred at $170 \mathrm{~min}$, some polyacrylamide microspheres were forced to move forward with water, and deposited and plugged other pores and pore throats in the sand pack. In the end, the injection pressure stabilized at about 1.8 MPa. Fig. 7(b) shows that for the sand pack treated with $0.5 \mathrm{wt} \%$ CPAM emulsion the injection pressure gradually increased to a peak value of 8.0 $\mathrm{MPa}$ and then decreased to a plateau level of 5.0 $\mathrm{MPa}$ when water was continuously injected. Fig. 7(c) and Fig. 7(d) indicate that when the solids contents in the emulsions were respectively $1.0 \mathrm{wt} \%$ and $2.0 \mathrm{wt} \%$, the variations of injection pressure with time were similar in the follow-up flow tests. At the beginning, the injection pressure increased slowly, but after $1 \mathrm{PV}$ water was injected, the injection pressure increased sharply. After injecting about 2 PV water, the injection pressure gradually stabilized at about $12 \mathrm{MPa}$.

This is because the polyacrylamide microspheres continued to swell due to hydrolysis, and the swollen microspheres may adsorb and deposit in the pores and pore throats so as to block the flow channels well. Moreover, the swollen polyacrylamide microspheres had a certain ability to block the flow channels for a long time without being displaced by flooding fluids. Injection of CPAM emulsion of higher solids content into the sand pack means that more polyacrylamide microspheres absorbed and deposit in the pores and pore throats. For formations with similar permeability, more microspheres lead to higher injection pressure.

Table 4 lists the permeability reduction performance of CPAM emulsions with different solids contents. As can be seen from the table, when the solids contents were $0.5 \mathrm{wt} \%, 1.0 \mathrm{wt} \%$ and $2.0 \mathrm{wt} \%$, respectively, the rate of permeability reduction of all the sand packs were more than $99 \%$. Therefore, from the economic perspective, the CPAM emulsion of solids content of $0.5 \mathrm{wt} \%$ or $1 \mathrm{wt} \%$ was recommended. 


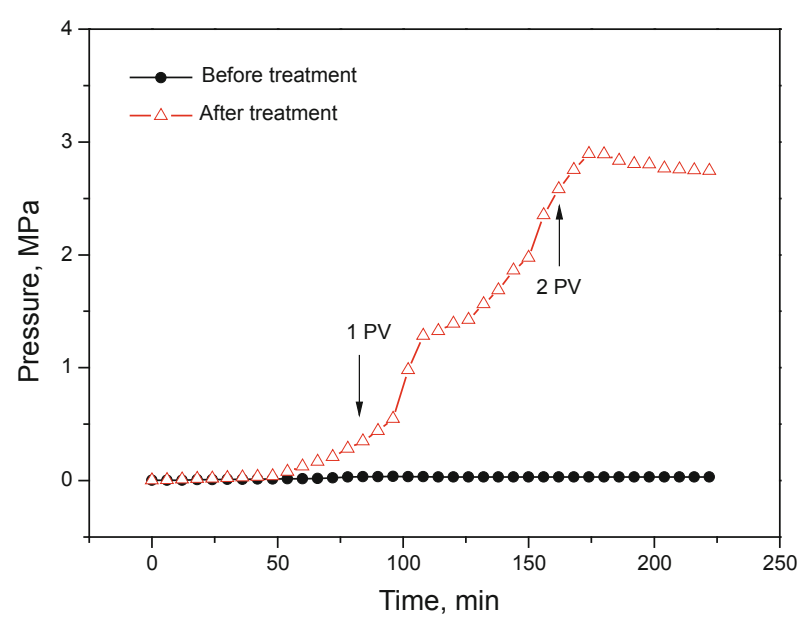

(a) A solid content of $0.3 \mathrm{wt} \%$

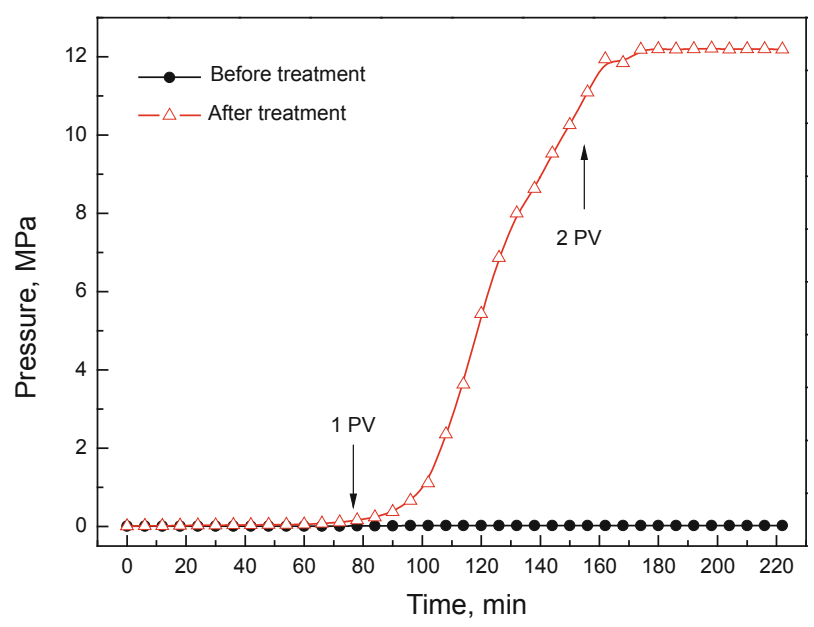

(c) A solid content of $1 \mathrm{wt} \%$

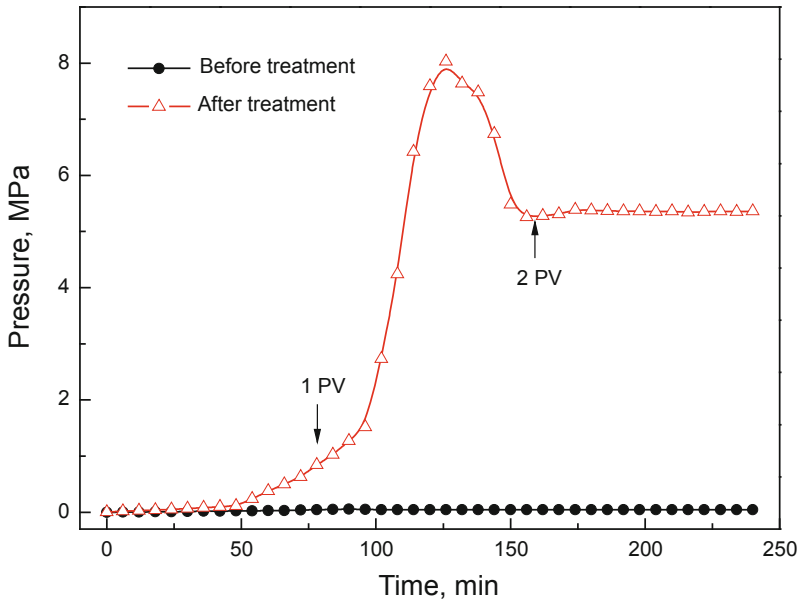

(b) A solid content of $0.5 \mathrm{wt} \%$

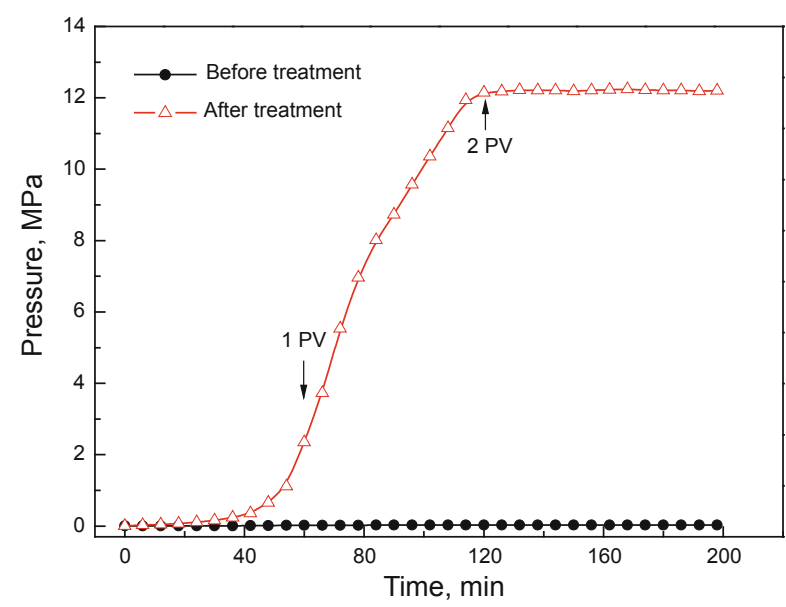

(d) A solid content of $2 \mathrm{wt} \%$

Fig. 7 Curves of injection pressure with time before and after treatment with CPAM emulsions of different solids contents

Table 4 Permeability reduction performance of CPAM emulsion

\begin{tabular}{|c|c|c|c|c|c|c|}
\hline No. & $\begin{array}{c}\text { Solids content in CPAM } \\
\text { emulsion, } \mathrm{wt} \%\end{array}$ & $\begin{array}{c}\text { Pore volume } \\
\text { L }\end{array}$ & $\begin{array}{c}\text { Initial porosity } \\
\%\end{array}$ & $\begin{array}{l}\text { Initial permeability } \\
\text { to water } K_{0}, \mathrm{mD}\end{array}$ & $\begin{array}{l}\text { Post-treatment permeability } \\
\text { to water } K, \mathrm{mD}\end{array}$ & $\begin{array}{c}\text { Rate of permeability } \\
\text { reduction, } \%\end{array}$ \\
\hline 1 & 0.3 & 0.30 & 27.1 & 483 & 40.8 & 91.6 \\
\hline 2 & 0.5 & 0.29 & 26.5 & 339 & 2.78 & 99.2 \\
\hline 3 & 1.0 & 0.30 & 27.2 & 702 & 1.28 & 99.8 \\
\hline 4 & 2.0 & 0.30 & 26.9 & 504 & 1.20 & 99.8 \\
\hline
\end{tabular}

\subsubsection{Effect of formation permeability}

After hydrolysis at $65{ }^{\circ} \mathrm{C}$ for $24 \mathrm{~h}, 0.3 \mathrm{PV}$ CPAM emulsion with a solids content of $1 \mathrm{wt} \%$ was injected into the sand packs with different permeability. Before and after CPAM emulsion injection, flow tests were conducted and the curves of injection pressure with time are shown in Fig. 7.

Fig. 7(a) shows that for low permeability formations treated with $0.3 \mathrm{PV}$ CPAM emulsion, the injection pressure increased sharply before $62 \mathrm{~min}$ (1 PV water), and then slowed down. After $140 \mathrm{~min}$, the pressure stabilized.
The CPAM may effectively reduce the permeability of low permeablility formations. For medium permeability formations, the injection pressure increased slowly at the beginning, while grew fast after 2 PV water injection, and still presented a growing trend after 3 PV water was injected. Moreover, the injection pressure of entire process was not very high, less than 1.0 MPa. For high permeability formations, the maximum injection pressure was only 0.017 $\mathrm{MPa}$, which was a little higher than the injection pressure of the sand pack before being treated with CPAM emulsion. 


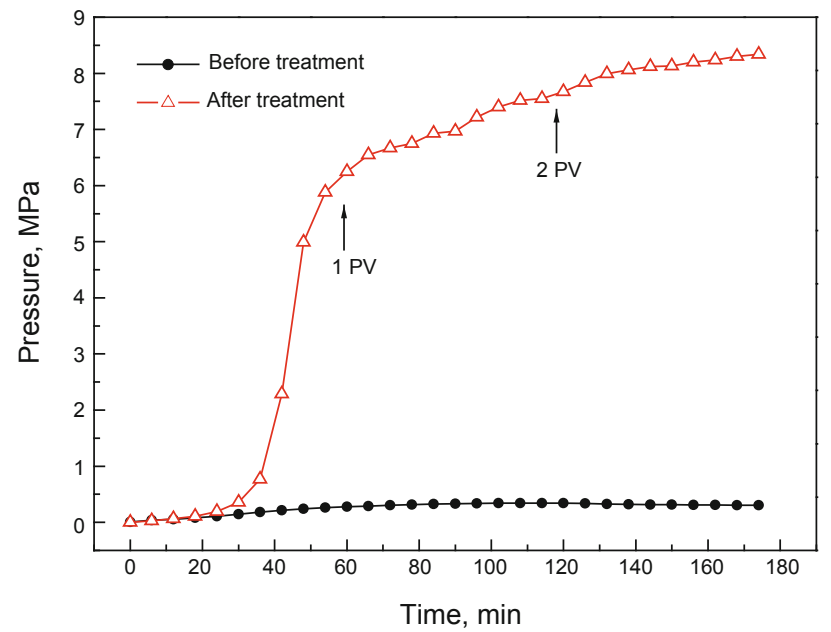

(a) Sand pack with low permeability of $53 \mathrm{mD}$

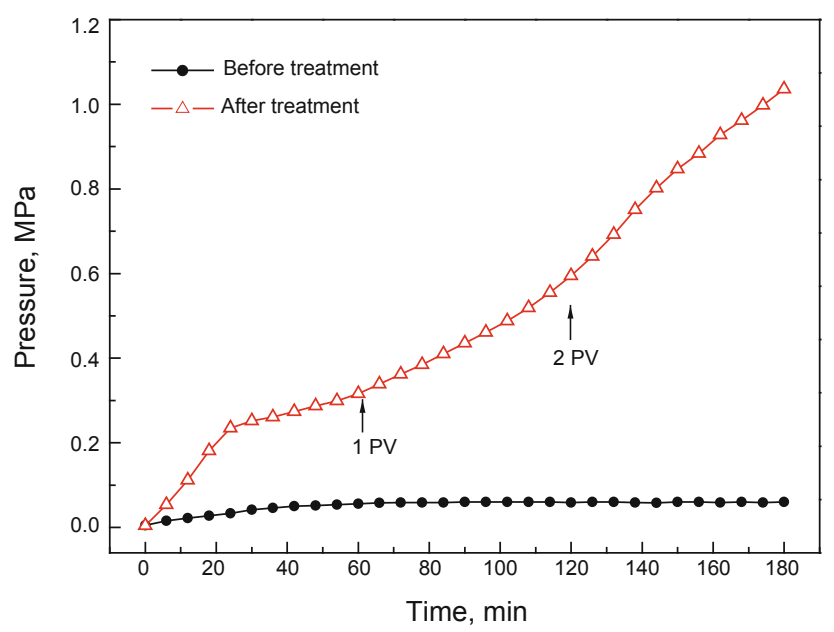

(b) Sand pack with medium permeability of $237 \mathrm{mD}$

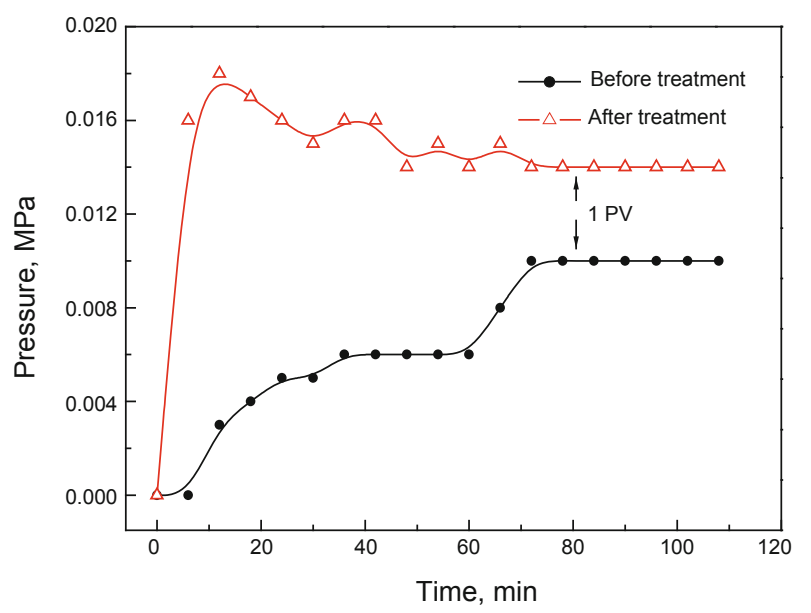

(c) Sand pack with high permeability of $1427 \mathrm{mD}$

Fig.8 Injection pressure of CPAM emulsion versus injection time in different permeability sand packs

Therefore, the CPAM emulsion could not effectively reduce the permeability of high permeability formations. Table 5 lists the permeability of sand packs before and after injection of CPAM emulsion. Table 5 shows that the CPAM emulsion of a solids content of $1 \mathrm{wt} \%$ may reduce the permeability of low-to-medium permeability formations by more than $90 \%$; while for high permeability sand packs of over $1,000 \mathrm{mD}$, the CPAM emulsion performed poorly, reducing the sand pack permeability by less than $30 \%$. Hence, the CPAM can be used in profile modification of low-to-medium permeability formations, but not in high permeability formations.

Table 5 Performance of CPAM for permeability reduction of different permeability sand packs

\begin{tabular}{cccccc}
\hline No. & $\begin{array}{c}\text { Pore } \\
\text { volume, L }\end{array}$ & $\begin{array}{c}\text { Initial } \\
\text { permeability to } \\
\text { water } K_{\mathrm{o}}, \mathrm{mD}\end{array}$ & $\begin{array}{c}\text { Porosity } \\
\%\end{array}$ & $\begin{array}{c}\text { Post-treatment } \\
\text { permeability } \\
\text { to water } K, \mathrm{mD}\end{array}$ & $\begin{array}{c}\text { Rate of } \\
\text { permeability } \\
\text { reduction } \\
\%\end{array}$ \\
\hline 7 & 0.22 & 53 & 19.9 & 2.07 & 96.1 \\
8 & 0.30 & 237 & 27.3 & 14.4 & 93.9 \\
9 & 0.33 & 1426 & 29.7 & 1030 & 27.8 \\
\hline
\end{tabular}

\section{Conclusions}

Cationic polyacrylamide microspheres (CPAM) were synthesized using the dispersion polymerization method and were systematically characterized. Flow tests were conducted on sand packs before and after treatment with CPAM emulsions to investigate the performance of CPAM to control formation permeability. The following conclusions are drawn.

1) The optimized conditions for CPAM polymerization are as follows: the dosage of stabilizer (PAETAC) at about $0.5 \mathrm{~g} / \mathrm{g}$-monomer, AM to DMC molar ratio at 8:2, ammonium sulfate concentration at $27 \mathrm{wt} \%-30 \mathrm{wt} \%$, APS (initiator) concentration at $1 \mathrm{wt} \%$, and reaction temperature at $50-55{ }^{\circ} \mathrm{C}$. Under these conditions, a uniform polymer emulsion with higher viscosity and good stability was obtained.

2) Cationic polyacrylamide can be hydrolyzed under basic conditions of $\mathrm{pH}=9$, and its particle sizes increase by more than ten times during hydrolysis. The swollen polyacrylamide microspheres are neat and regular.

3) The CPAM emulsion of a solids content of $0.5 \%-2.0 \%$ may effectively reduce the permeability of low-to-medium permeability formations, and 99\% permeability reduction was achieved. While for high permeability formations exceeding $1,000 \mathrm{mD}$, only $28 \%$ permeability reduction was achieved.

\section{Acknowledgements}

The authors are grateful for financial support from the National Natural Science Foundation of China (Grants Nos. 51203186, U1362101 and 51173203), the Converging Research Center Program funded by Korean Ministry of Education (2013K000415), and the Project of Science and Technology Program for Basic Research of Qingdao (No. 121-4-7-(6)-jch).

\section{References}

Cho M S, Yoon K G and Song B K. Dispersion polymerization of acrylamide in aqueous solution of ammonium sulfate: synthesis and characterization. Journal of Applied Polymer Science. 2002. 83(7): 1397-1405

Dong Z X, Lin M Q, Wang H, et al. Influence of surfactants used in 
surfactant-polymer flooding on the stability of Gudong crude oil emulsion. Petroleum Science. 2010. 7(2): 263-267

Feng Q H, Shi S B, Wang S, et al. Numerical simulation of profile control by clay particles after polymer flooding. Petroleum Science. 2010. 7(4): 509-514

Fielding R C, Gibbons D H and Legrand F P. In-depth drive fluid diversion using an evolution of colloidal dispersion gels and new bulk gels: an operational case history of the North Rainbow Ranch unit. SPE/DOE Improved Oil Recovery Symposium, 17-20 April, 1994, Tulsa, Oklahoma (SPE/DOE 27773)

Fletcher A J P, Flew S, Forsdyke I N, et al. Deep diverting gels for very cost-effective waterflood control. Journal of Petroleum Science and Engineering. 1992. 7(1-2): 33-43

Grazon C, Rieger J, Sanson N, et al. Study of $\operatorname{poly}(N, N-$ diethylacrylamide) nanogel formation by aqueous dispersion polymerization of $\mathrm{N}, \mathrm{N}$-diethylacrylamide in the presence of poly(ethylene oxide)-b-poly( $N, N$-dimethylacrylamide) amphiphilic macromolecular RAFT agents. Soft Materials. 2011. 7(7): 3482-3490

Hou J, Du Q J, Lu T, et al. The effect of interbeds on distribution of incremental oil displaced by a polymer flood. Petroleum Science. 2011. 8(2): 200-206

Lei G L, Li LL and Nasr-EI-Din H A. New gel aggregates to improve sweep efficiency during water flooding. SPE Reservoir Evaluation \& Engineering. 2011. 14(1): 120-128

Lin M Q, Han F X, Li M Y, et al. Study of plugging performance of LPS with nucleopore film. Membrane Science and Technology. 2003. 23(2): 11-14 (in Chinese)

Lin M Q, Zhang C L, Zong H, et al. Influence of polymers on the stability of Gudao crude oil emulsions. Petroleum Science. 2008. 5(2): 159-162

Lin M Q, Zhao Z H, Li M Y, et al. The effect of surface wettability of porous media on the plugging properties of LPS. Acta Petrolei Sinica (Petroleum Processing Section). 2009. 20(5): 48-52 (in Chinese)

Lin M Q, Dong Z X, Peng B, et al. Shape, size and plugging properties of crosslinked polyacrylamide microspheres. Acta Polymerica Sinica. 2011a. (1): 48-54 (in Chinese)

Lin M Q, Guo J R, Xu F Q, et al. Study of the matching between cross-linked polymer microspheres and nuclear-pore membranes. Advanced Materials Research. 2011b. 160-162: 1346-1353

Liu H Q, Zhang H L and Wang S L. Research on mechanisms of steam breakthrough and profile control design for steam soaking well. Petroleum Science. 2006. 3(3): 51-55

Liu J, Wang C X and Wu Y M. Aqueous dispersion polymerization of acrylamide in ammonium chloride solution with water-soluble chitosan as a stabilizer. Iranian Polymer Journal. 2011. 20(11): 887896

Liu J, Wang C X and Wu Y M. Dispersion polymerization of acrylamide with water-soluble chitosan as the stabilizer. Journal of Applied Polymer Science. 2012. 125(2): 518-525

Lu J, Peng B, Li M Y, et al. Dispersion polymerization of anionic polyacrylamide in an aqueous salt medium. Petroleum Science. 2010.
7(3): 410-415

Lu X G, Liu J X, Wang R J, et al. Study of action mechanisms and properties of $\mathrm{Cr}^{3+}$ cross-linked polymer solution with high salinity. Petroleum Science. 2012. 9(1): 75-81

Ning Z F, Liu H Q and Zhang H L. Steam flooding after steam soak in heavy oil reservoirs through extended-reach horizontal wells. Petroleum Science. 2007. 4(2): 71-74

Ondaral S, Usta M, Gumusderelioglu M, et al. The synthesis of water soluble cationic microgels by dispersion polymerization: their performance in kaolin deposition onto fiber. Journal of Applied Polymer Science. 2010. 116(2): 1157-1164

Qiao R, Zhang R, Zhu W Q, et al. Lab simulation of profile modification and enhanced oil recovery with a quaternary ammonium cationic polymer. Journal of Industrial and Engineering Chemistry. 2012. 18(1): 111-115

Semsarilar M, Ladmiral V, Blanazs A, et al. Cationic polyelectrolytestabilized nanoparticles via raft aqueous dispersion polymerization. Langmuir. 2012. 29(24): 7416-7424

Shi L T, Ye Zhong B, Zhang Z, et al. Necessity and feasibility of improving the residual resistance factor of polymer flooding in heavy oil reservoirs. Petroleum Science. 2010. 7(2): 251-256

Shi L T, Chen L, Ye Z B, et al. Effect of polymer solution structure on displacement efficiency. Petroleum Science. 2012. 9(2): 230-235

Song B K, Cho M S, Yoon K J, et al. Dispersion polymerization of acrylamide with quaternary ammonium cationic comonomer in aqueous solution. Journal of Applied Polymer Science. 2003. 87(7): 1101-1108

Wang B and Li M Y. Plugging properties of novel profile control agent carboxymethyl starch. Journal of Petrochemical Universities. 2011. 24(1): 86-88 (in Chinese)

Wang X N, Yue Q Y, Gao B Y, et al. Kinetics of dispersion polymerization of dimethyl diallyl ammonium chloride and acrylamide. Journal of Polymer Research. 2011a. 18(5): 1067-1072

Wang C X, Wang X X, Miao C B, et al. Preparation and properties of amphoteric polyacrylamide by seeded dispersion polymerization in ammonium sulfate solution. Polymer Engineering \& Science. 2011b. 51(9): 1742-1748

Wang X N, Yue Q Y, Gao B Y, et al. Dispersion copolymerization of acrylamide and dimethyl diallyl ammonium chloride in ethanolwater solution. Journal of Applied Polymer Science. 2011c. 120(3): 1496-1502

Wu Y M, Chen Q F, Xu J, et al. Aqueous dispersion polymerization of acrylamide with quaternary ammonium cationic comonomer. Journal of Applied Polymer Science. 2008. 108(1): 134-139

Xiao C M and Wang Z L. Review of profile and water plugging in oilfields. Advances in Fine Petrochemicals. 2003. 4(3): 43-46 (in Chinese)

Yu H, Wang Y, Ji W, et al. Study of a profile control agent applied in an offshore oilfield. Petroleum Science and Technology. 2011. 29(12): 1285-1297

(Edited by Sun Yanhua) 